\title{
Chapter 13 \\ Energy Justice and Intergenerational Ethics: Theoretical Perspectives and Institutional Designs
}

\author{
Giuseppe Pellegrini-Masini $\mathbb{D}$, Fausto Corvino $\mathbb{D}$, and Lars Löfquist
}

\begin{abstract}
In this work, we discuss how both contractualism, in the Western tradition, and communitarianism, in the African interpretation based on the idea of Ubuntu, conceptualise intergenerational justice. Even though both philosophical theories, taking into account differences and shortcomings, provide theoretical answers to intergenerational justice dilemmas, the implementation of actual policies in the interest of future individuals does not follow straightforwardly. Accordingly, in the second part of the chapter, we analyse what policy tools have been implemented or conceived to deliver intergenerational justice and we advocate a pragmatic approach pointing towards a mix of different policy tools.
\end{abstract}

\subsection{Introduction}

Energy justice is a relatively new theoretical framework for understanding the sustainability of the energy system and the allocation of burdens and benefits among all those actors that are involved in its various phases: those who produce, deliver, and consume energy and those who are called to manage the corresponding waste. McCauley (2018: 1-2) has recently defined energy justice as "the application of rights (both social and environmental) at each component part of the energy system". As any distributive scheme concerned with the assignment of social rights and the correlative duties among the members of society, energy justice brings with itself the problem of defining its scope. What are the geographical (or political) and the temporal borders that delineate the group of individuals whose rights and duties

\footnotetext{
G. Pellegrini-Masini

NTNU Norwegian University of Science and Technology, Trondheim, Norway

e-mail: giuseppe.p.masini@ntnu.no

F. Corvino

Sant'Anna School of Advanced Studies, Pisa, Italy

L. Löfquist

Uppsala University, Uppsala, Sweden
} 
should be taken into consideration when referring to energy justice? Both issues are particularly pressing in the energy justice discourse, even more than in classic disputes of distributive justice, given that both economic gains and negative externalities stemming from the phases of the energy system tend to be global in the geographical extension and misaligned in time, the classic example being climate change.

In this chapter, we discuss the temporal aspect of the scope of energy justice. More precisely, we tackle the question of whether future people should be considered as participants in the scheme of redistribution that underpins the ideal of energy justice. In doing this, we firstly confront two prominent theories of distributive justice that have been constantly juxtaposed in the literature on political philosophy, starting from the second half of the twentieth century. The first one is the social contract theory, which we consider in the classic formulation given by John Rawls, in the moral variant proposed by Thomas Scanlon, and in the contractarian, version devised by David Gauthier. The second one is communitarianism, not simply in the Western formulation given in the literature on liberalism, but also through the lens of the African political philosophy of Ubuntu. Lastly, we discuss how the philosophical concerns for future beings have been translated into specific policies, with the aim of weighing the interests of present individuals against the social rights of posterity.

In pursuing this discursive path, we unfold our analysis in line with the approach taken by Sanusi and Spahn (in this volume), which is based on the dualism between an individualistic conception of human beings as utility maximisers (that they exemplify quite generally with the West) and a communitarian view on human relations (that they exemplify in the vision of Ubuntu). Yet, differently from them, we are mainly interested in investigating the intergenerational offshoots of these philosophical accounts and the public policies that they can substantiate.

\subsection{Contractualism and Intergenerational Justice}

In Western moral theory, contractualism is the doctrine according to which the rightness of any action can only be tested against the terms of a hypothetical agreement between free and equal people. In political theory, the ideal of an impartial agreement is mainly used to test the legitimacy of political power. Within political contractualism, it is possible to distinguish between Kantian versions of contractualism, in which people decide to conform to an impartial agreement because they are moved by the moral need to make inequalities justifiable to everybody, and Hobbesian versions of contractualism, where the primary impulse towards bargaining is for the individual to guarantee himself the maximum expected payoff.

In both moral and political theory, the problem with reconciling the idea of the contract with concerns of intergenerational justice is basically the same. If we assume that our obligations of justice stem from an agreement that we reach in a hypothetical bargaining situation, does it make sense to say that these obligations 
also extend to people who are not born yet? A great deal revolves around the issue of why people should decide to look for an agreement in the first place and why they should conform to it thereafter. If they do it for reasons of reciprocity or mutual advantage, it becomes difficult to explain why the bargaining parties should take into consideration the interests of those people who cannot reciprocate because they are not yet born. In addressing this theoretical point, we shall consider contractualism in a transversal way, passing through moral and political theory and looking at three different bargaining models. The first one is the semi-political model of contractualism famously proposed by John Rawls in A Theory of Justice and later amended and integrated in subsequent works. Very briefly, Rawls considers society as a "cooperative venture for mutual advantage". By joining among them, people manage to yield, in absolute terms, more wellbeing than they would have were they to remain by their own (Rawls 1999: 4). However, a significant political problem is that those with more talent and with more resources will advance larger claims on the benefits stemming from cooperation. So, how do we justly divide the cooperative surplus? The answer provided by Rawls is in a fair way. In order to do so, Rawls returns to a thought experiment. He asks us to imagine all the participants in the cooperative venture in an "original position", where they are covered by a "veil of ignorance", meaning that they do not know their personal qualities and their social position, while simply having basic knowledge about politics, economics, and human affairs (Rawls 1999: 10-19, 118-123). Rawls' conclusion is that under such circumstances, the rational strategy for self-interested individuals would be to adopt a principle of socio-economic justice, named the "difference principle", according to which "social and economic inequalities are to arranged so that they are [...] reasonably expected to be to everyone's advantage"(Rawls 1999: 53).

A second contractualist model, although some authors prefer to call it contractarian (see Cudd and Eftekhari 2018), is the Hobbesian interpretation of the bargaining for the cooperative surplus that was proposed by David Gauthier (1987). Here there is no veil of ignorance. Economic agents perfectly know who they are and which social and individual strengths they can rely upon during the session of the social contract. This means that there are no moral premises in the structuring of the initial bargaining situation, because the parties seek to maximise their individual payoff starting from positions that have not been hypothetically levelled out. Gauthier maintains that under these circumstances, the parties would be stuck in something like a prisoner's dilemma. The best collective strategy is to cooperate, in order to yield the cooperative surplus. Yet, every agent would find it rational to defect while others cooperate, in order to maximise her personal payoff and avoid the cost of cooperation. The risk, clearly, is that if every agent seeks the choice that is individually rational, i.e. freeriding, we end up in the worst outcome, both from the individual and the collective point of view-the non-cooperative equilibrium (Gauthier 1987: 113-156).

Given these premises, Gauthier argues, the bargaining parties have an interest in reaching an agreement and later in securing it, but at the same time, the best individual outcome is the one in which the agreement is obtained with the single agent making no concessions at all. Obviously, given the cooperative nature of the first 
objective, it is not reconcilable with the second one, because self-interested agents would become stuck in a non-cooperative equilibrium. Therefore, Gauthier maintains that in drafting the social contract, the rational individual strategy consists in following the rule of the "minimax relative concession", according to which each agent makes subsequent concessions in relation to her best outcome, under the condition that each concession is reasonable in comparison to the ones made by other parties. The result, in theory, would be an agreement that makes society better off at the lowest individual cost for everyone (Gauthier 1987: 136-137).

Lastly, a third formulation of the contractualist idea is the model of reasonable non-rejectability that has been developed by Thomas Scanlon. He argues that an action is morally right if others cannot reasonably reject it after having been properly motivated. More generally, the rightness or wrongness of any action depends on whether it would be allowed or disallowed by a "set of principles for the general regulation of behaviour that no one could reasonably reject as a basis for informed, unforced, general agreement" (Scanlon 1998: 153). Obviously, any redistribution of resources is supposed to worsen the wellbeing of some individuals while benefiting some others. Given that in Scanlon's contractualism there is no veil of ignorance, the "losers" of redistribution, no matter how well off they are, would have reasons to oppose the redistributive policy from their specific social position. Yet, wellbeing is not the only thing that matters for the purpose of justification. The "winners" of redistribution might counter-oppose arguments based on the principle of fairness, of compensation for harm, of restitution for unjust enrichment, and so on. In the end, every person is required to weigh his reasons for action against others' reasons in an impartial way: an action that has passed this test is morally right.

From these brief remarks, it follows that the problem of future people can find a theoretical solution in Scanlon's moral contractualism, while it is more difficult to find space for posterity in Rawls' theory and extremely difficult in Gauthier's model. Regarding the first point, since in moral contractualism individuals are not seeking the right principles to split the cooperative surplus, but only those that others could not easily reject, the obstacle of non-reciprocality becomes negligible. Even though the present generation cannot enter in a mutually beneficial relation with future ones, provided that present actions can potentially affect the wellbeing of future individuals, there is no reason why present individuals should not weigh their reasons for action against the hypothetical counter-objections that might be moved by future individuals (see Ashford 2018). Moreover, given that moral contractualism is not aggregative as utilitarianism is, the fact that only a small group of future people might have reasons to reject an action that a large group of present people approve is not enough to make it morally acceptable, because we only have to take into consideration the weight of the reasons in favour and against this action regardless of the number of people positioned on the two sides of the dispute (Southwood 2009; Ashford 2003).

Yet, the complication when reasoning about energy justice is that we can only speculate about what reasons future people would have to reject our present actions, and in doing this, we do not have a precise knowledge about the technological capacities and the environmental conditions of the future societies that might suffer the consequences of past actions. Consider, for example, the basic case of over- 
appropriation of fossil fuels by the present generation. In assessing the weight of the counter-arguments that might be raised by future people on the ground of justice in appropriation and of fairness in the allocation of negative externalities, we should predict how much future people would have to rely on fossil fuels versus renewable energy and what is the remaining quantity of $\mathrm{CO}_{2}$ emission that the environment could absorb before being irremediably damaged.

When reasoning about contractualist models based on the expected benefits of cooperation, the huge obstacle we encounter, instead, has to do with the fact that reciprocity between generations can only be indirect (Gardiner 2009), and indirect reciprocity does not account for cooperation for the purpose of mutual advantage. Admittedly, Rawls has long pondered over this problem and has progressively changed his mind about it. His first solution, proposed in A Theory of Justice, consisted of arguing that the difference principle cannot be applied to different generations, because even though the veil of ignorance prevents them from knowing which specific generation they belong to, they know they are contemporaries; hence, they would have no reason as agents aiming to maximise their payoff, to redistribute towards future individuals. Nonetheless, Rawls adds that if we look at the parties as "heads of families", who care for their next descendants (Rawls 1971: 128-129), we can expect them to agree to an intergenerational "just saving principle" that constrains the application of the difference principle among contemporaries and is aimed at preserving the basic conditions for justice over time (Rawls 1971: 289).

In later works, Rawls postulated that the parties would agree on a just saving principle, for the mere reason that they "must want all previous generations to have followed it" (Rawls 2005: 274). Whether Rawls could have found a better solution for dealing with future generations remains an open issue. On the one hand, there is no apparent contractualist reason why an agent in the original position might find it rational to save for future people, rather the only thing she may wish for is that the previous generations have saved for her. On the other hand, Rawls maintains that there is a pre-existent duty to secure justice over time, and he seeks to anchor the just saving principle to it. Yet, as rightly stressed by Heyd (2009), this intergenerational commitment is moral rather than political, because it has nothing to do with fairness; hence, the just saving principle should be considered as a principle for securing justice rather than as a principle of justice tout court.

Nonetheless, against Rawls and against those who criticise Rawls for insisting on a principle of intergenerational redistribution where no cooperation occurs, the objection that a form of direct reciprocity is inherent in the fact that generations are porous sets that continuously overlap may also be raised. In any moment in history, there would be people from two or three (or even more) different generations coexisting at the same time, and obviously these generations need to cooperate among each other. David Gauthier follows this line of reasoning when he maintains that in dealing with future individuals, we do not need to drop the "assumption of mutual unconcern", because every individual has an interest in securing an agreement with those who overlap his generation (Gauthier 1987: 299).

Talking about energy, just think, for example, about a policy that maximises the wellbeing of the people that are likely to die within 30 years from now, while leav- 
ing the biggest share of the costs - in terms of pollution and of adaptation needs- to those who will live during the next 90 years from now. Some of the people from the second group — namely, those who will die between the next 30 and 90 years-are already in existence; hence, we can expect them to oppose this policy on the grounds that it would be an unfair way to allocate burdens and benefits of social cooperation. Accordingly, we might be tempted to argue that indirect reciprocity is a false problem, because social cooperation unifies subsequent generations in an infinite chain of justice. Yet, the limit of this approach is that it does not work with the socalled "time bombs". That is to say with those situations in which negative externalities can be deferred far in time.

Radioactive wastes serve as a classic example of the time bomb dilemma. Assume that all the people who are alive at this moment in a given country were to decide where to stock all their radioactive wastes and how to do it. Consider two options. Option A: we invest $\mathrm{N}$ money and in so doing, we ensure that the radioactive waste containers will be safe for an indefinite period of time, only requiring future people to provide for minor maintenance. Option B: we invest $\mathrm{N} 1<\mathrm{N}$ money though which we built containers that will only keep for the next 200 years, and thereafter our descendants will have to spend $\mathrm{N} 2>\mathrm{N}>\mathrm{N} 1$ money to build a new stocking implant - that is to say, they will have to shoulder the costs of past negative externalities without having enjoyed the correlative benefits. Do we have a duty of contractualist intergenerational justice to choose Option A? The answer is probably negative, because we do not overlap with anyone who will live 200 years from now, and we are not really sure that something like the just saving principle would compel us to choose Option A. This really depends on how we nail down this principle, both in relation to the current level of development and also to the issue whether selecting Option B might jeopardise the chance future people will have of maintaining just social institutions. The odds are that the just saving principle would not suffice to prevent us from leaving the burden of radioactive waste to future people, although this might seem, intuitively, a clear case of unfairness.

To conclude this section, adapting contractualist models to the demands of intergenerational justice presents us with three problems that are exacerbated when dealing with energy systems. First, if we return to a model of moral contractualism à la Scanlon, we do not have many troubles in explaining why we have to justify our actions to future individuals, but we are left with no political arguments to spend with mutually unconcerned individuals who are willing to accept the burdens of socio-economic justice only on condition that we demonstrate that this is the most rational strategy for them. Second, if we opt for a political contractualism à la Rawls, that is to say constrained by the veil of ignorance, we end up with a just saving principle that is incapable of sanctioning the unfairness in the distribution of benefits and negative externalities stemming from the production, distribution, and consumption of energy. Third and lastly, if we embrace Gauthier's political contractualism, we would have good justifications to offer to those people who even refuse the moral preconditions that Rawls imposes on the political bargain, but we remain helpless in cases like "time bombs" where generations do not overlap. 


\subsection{A Communitarian View on Intergenerational Justice}

Another possible solution for building up a coherent set of intergenerational principles of justice might consist of moving to a different methodological premise. Instead of looking at individuals as separate maximisers of their own wellbeing, or "mutually disinterested" beings who struggle with each other for securing the widest possible share of the cooperative surplus, under more or less pronounced moral restraints related to the initial bargaining situation, we might want to centre our analytical focus on the community as a whole. Here, community is interpreted as a group of people who share the same social and cultural features and who are tied in the achievement of common ends. This part of the chapter will take a closer look at communitarianism in general and a specific African conception of the community.

Communitarianism is a broad term applicable to a range of philosophical positions and perspectives in political philosophy and meta-ethics. A central claim made by all communitarian thinkers is a strong rejection of the idea that there are universal values in any thick sense of the word. All comprehensions of value are relative to a specific point of view. It is possible to compare different points of view, but it is not possible to assume what Nagel calls "a view for nowhere" (Nagel 1989). Rawls contractarian ideas and "the original position" (Rawls 1999) are based on an abstraction of human beings that have little relevance to the real-world humans who are all deeply imbedded in language and culture (Taylor 1989; Sandel 1981; Walzer 1983). Thus, the communitarians reject the ontological and methodological assumption in the contractualist thinkers we have investigated so far. In MacIntyre's (1989, 2006) terminology, there are several moral traditions that are not only different, but might have conflicting interpretations of values and justice. This conflict cannot be solved by trying to apply a more rational universal point of view given that even the conception of rationality is based on specific intellectual traditions and we lack criteria to select which tradition that is most reasonable.

A communitarian comprehension of intergenerational justice is articulated by De-Shalit. A community is understood here as consisting of both past generations, current generations, and future generations. Thus, the present-day Jewish community considers itself to be part of a long history of communities that share norms, worldview, and practices. This community will also include future people who will share these commonly held beliefs. The different generations share a common identity of what it means to be part of the Jewish community, and they also share an ongoing discourse of what "Jewishness" means (De-Shalit 1995).

Justice in a communitarian perspective is primarily applicable inside a community since the members share special responsibility to its members. That does not imply that there is no moral responsibility towards non-members, but that such responsibility is based on another moral foundation, humanity (De-Shalit 1995). This raises several important considerations: First, how long into the future should the community be extended? Second, how strong are the responsibilities to future non-members? The current communitarian political philosophy has been developed in the Anglo-American discourse on liberalism and its associated theories of justice. However, the general idea that individuals need to be understood as parts of a 
community and that our identity is formed in this community is not restricted to this discourse. Philosophers from sub-Saharan Africa define an example of ideas that have a similar perspective on the individual and the group, for instance.

There are numerous problems with trying to generalise about African thinking. The greatest risk is to use conceptual resources developed outside of these contexts to translate ideas that should be conceived as unique. Still, there are those that argue that there is an African conception of how a community should work (e.g. Mbiti 1969; Menkiti 2017; Praeg 2008; Eze 2008). This conception is not the same as communitarianism in Western philosophy, but it is beneficial to methodologically treat it as a special kind of communitarianism since that makes it easier to compare with other mainstream theories in Western political philosophy, especially contractualist theories. At the same time, we must be careful of not reducing the uniqueness of this tradition while translating it into foreign concepts. Nevertheless, African philosophers themselves use the terminology "African Communitarianism", therefore providing us with grounds for sticking to the same term of communitarianism (Eze 2008).

The key concept in African communitarian thinking is Ubuntu. This is a panAfrican idea with several linguistic forms, and a simple translation is not possible. As noted by Praeg (2008), the content of Ubuntu is both novel and unique. Treating it as something totally untranslatable would be an exaggeration, but treating it as simply as an African kind of communitarianism would be wrong too. He also notes that we can separate the discourse about Ubuntu as political philosophy, e.g. communitarianism, with the workings of Ubuntu, e.g. sacred rituals in the village life. Both dimensions are concerned with the interdependence between humans (Praeg 2008).

One famous way to sum up the concept of Ubuntu is provided by Mbiti: "I am, because we are" (1969: 109). According to one interpretation of this statement, this means that the individual is not separated from the community but is epistemologically and ontologically submerged in it. According to Eze, we cannot talk about individuals as freestanding; instead, we should use terms such as interrelatedness. Being a person is to be in a dialogical relationship with the community where each member has a responsibility to recognising each other as a person (Eze 2008: 387). Justice, then, should be understood from the backdrop of mutual recognition and responsibilities. This is a mutuality that should not be understood as a form of contractual obligations, but as sharing a common life where each individual has specific roles to play. Some thinkers argue that this interrelatedness can go beyond the human community and also include parts of the non-human nature (Chachine 2008; Lenkabula 2008). However, in what follows the analysis will focus on the interrelatedness between present and future humans.

In Mbiti's conception, Ubuntu as interrelatedness seems to support a social holism where individuals are downplayed compared to the group. The good is primarily communal and not individual (Chachine 2008: 51). Gyekye proposes a more nuanced approach. He argues that Mbiti's analysis fails to take individuals into account and that a social holism is an inadequate interpretation of Ubuntu. Gyekye propose that Ubuntu includes a balance between communal good and individual good. A "moderate communitarianism" must entail proper protection for individu- 
als, who retain their separate status despite the fact that they are immersed in the community (Matolino 2009: 163).

Thus, in the moderate communitarian form, Ubuntu does not mean that individuals are fused together with their community. The individual is still epistemologically and ontologically separate, but his or her identity is formed in the community and the individual good life must be found in the community. The common good consists of people living a good life in the community, and this involves each individual's unique subjectivity (Eze 2008). The common good could be conceived as a striving towards consensus between the members where the members adapt their individual pursuits to a degree where these pursuits are fused. Ideally, this would lead to a situation where distributional decisions are accepted as long as they are clearly the best means to protect or strengthen the common good. Yet Eze rejects this idea and argues that consensus will lead to totalitarianism. Instead, he argues that the guiding principle should be called realism. This principle means that we should recognise differences and make an honest attempt to understand the other's point of view. It is in the dialogue with different positions we can come to understanding and conversion of our beliefs (Eze 2008: 393-395). The distributional concern of justice can therefore not be abstracted from the relations in the community but must be shaped of the mutual recognition of such roles.

There are several forms of critique against the different interpretations of the Ubuntu concept. Sono (1994) criticises Ubuntu as glorifying the historical village life that in practice meant that some made decisions that had a significant negative impact on others (Sono 1994). Following Sono, one can argue that in order to answer distributive questions, it is necessary to prioritise some people's claims over other people's claims, and that can lead to a charge of unfairness and resentment. Such charges can be well justified especially when an individual's good is totally disregarded. Another critique is that the local life of the village has very little to do with the modern national states which include numerous groups who do not all share the same idea of the common good (Matolino and Kwindingwi 2013). In relation to this critique, some authors have argued that Ubuntu is an egalitarian utopic ideal that can provide us with a critical instrument on how to judge and plan our current society (Metz 2014).

If interrelatedness or interdependence is the core principle of Ubuntu, this concept should ideally include future generations. There is a relationship between current members of the community and future members since they share their identity. However, there is also a radical asymmetry between the generations in the form of power. Current generations have the power to affect the future ones, but the future ones could at most blame or praise the current ones. Another aspect of interrelatedness is tied to the recognition of each other as persons. Personhood requires recognition of others, presumably with face-to-face meetings as the paradigmatic example, which is not directly possible for future generations. This challenge can be met since recognition can take forms that do not fit the face-to-face form. Rituals that take the historical members of the community into account are concrete examples. 
Behrens (2012), who argues that a core African belief is that ancestors should be treated with respect, provides a rationale of how Ubuntu relates to future generations. This provides the foundations for two obligations. First, current generations need to treat the environment as an asset owned by generations. Second, current generations can show their respect towards their ancestors by passing on the benefits they received towards future generations (Behrens 2012: 181f). When the environment is conceived as a common good shared by different generations, it affects the attitude we have towards nature. Overusing, abusing, or damaging the environment robs future generations of their inheritance (Behrens 2012: 183, 187). The second obligation provides an indirect responsibility towards future generations since we can only show our own gratitude to our ancestors by passing on land and resources to those who come after us (Behrens 2012: 185).

How would we understand energy questions through the prism of Ubuntu? A hypothetical example would be if a village faced the need to electrify. The issue can be constrained to be a choice between different systems, such as whether the village should obtain a government loan to buy a small diesel generator, a wind turbine, or solar panels. Any discourse about these decisions would include information about technical feasibility, lifetime, and costs. The concept of Ubuntu also suggests that the discourse would include questions about how this will influence the villages' relation to other villages and the national state. It would take into account equity issue of how the different systems influence the common life of the village. Will everybody have a chance to enjoy lightning during the darkness? Will groups in the community have better access than others? If Ubuntu is seen as striving towards consensus, the discourse should lead to an agreement that would fuse the different interests into a shared decision. As pointed out by Eze (2008), the discourse could also lead to conversion where one particular position emerges as the most reasonable. However, it is perfectly possible that no specific decision will emerge. A key attitude held by the participants of the discourse is that whatever decision made, it must play proper respect to the ancestors and pass on something good to future generations. Thus, one can claim that a diesel-powered generator, which by dispersing $\mathrm{CO}_{2}$ emissions adds to climate change, will not be a fitting solution since it would be incompatible with passing on something good.

The connection between Ubuntu, intergenerational responsibility, and energy becomes more complex when we turn to large-scale energy systems such as hydro plants. The construction of such plants can not only affect numerous groups negatively, but also provide a positive overall effect on a nation. The main challenge with this case is that it can be argued that passing on a relatively stable source of electric power is the best way to honour the heritage of the ancestors. On the other hand, one can also argue that the construction of the plant will include a destruction of the environment that is owned by all generations of all communities. There is a clear risk that the two concepts conflict and that there is no clear normative path on how to prioritise between the claims of different generations.

The Ubuntu concept does not provide simple responses to the two questions previously asked about the limits to the community: How long into the future should the community be extended? How strong are the responsibilities to future nonmembers? One can argue that just because I might feel obligated to pass on 
something to future persons in my own community, that does not mean that I also have obligations to other communities. An indirect response to this claim is that interdependence extends to the relations between communities. Our own community cannot be separated from other communities, and the common good requires something else than simply focusing at the interests of different communities. As noted above, this might not avoid conflict of interests, but it provides an argument for finding ways to overcome such conflicts. Such solutions need to move beyond personal relations and the village life. They must consider the institutional systems that will strengthen and weaken the spirit of Ubuntu in practice.

\subsection{Intergenerational Energy Justice: Implementing Institutional Designs}

As we have argued in the previous sections, intergenerational justice is a complex theoretical problem that can be addressed, but not without some caveats by the contractualist tradition, and perhaps more easily by the communitarian philosophical tradition.

In this last section, we will move on to discussing some of the policy attempts and proposals that have been made to address the problem of considering the interests of future generations in policymaking. These could be implemented to deliver some degree of intergenerational energy justice. In doing so, we recognise the importance of delivering a policy grounded approach to the philosophical discussion regarding intergenerational energy justice. The reason might be obvious to many: the urgency of the global environmental problems caused by climate change is a stark reminder that we need to confront ourselves with viable immediate policy solutions for implementing otherwise merely theoretical ideas.

Intergenerational energy justice does not have an established definition per se, even though recently an attempt at defining this concept has been made: "... as a state of policies conducive to an equitable distribution of finite natural and nonrenewable energy resources aimed at avoiding any severe damage of the biosphere, which takes account of the equal dignity and of equality of rights of different generations, even when living in distant times" (Pellegrini-Masini et al. 2019a: 5), whereas "intergenerational energy equity", considered by several authors as one of the constituting principles of energy justice, has been defined as follows: "Future generations have a right to enjoy a good life undisturbed by the damage our energy systems inflict on the world today" (Sovacool et al. 2017: 687).

The challenges in establishing energy intergenerational justice lie in devising and implementing those policies that are considered necessary to deliver an equitable distribution of energy resources, particularly because the representation of the interests of future generations can be regarded only limitedly effective when it is delivered through democratically elected parliaments. In fact, we can assume that the elected representatives will, to some extent, also represent the interest of their immediate descendants (as we noted in earlier sections), but they will be less likely 
to be concerned with the interests of generations living in the far future. The shorttermism of current parliaments has already been highlighted with regard to financial sustainability and, to lesser extent, environmental sustainability (Tremmel 2006a), although the arguments that underpin this problem might be considered the same, particularly when it is argued that they are motivated by people's "perception" and "ideology" (Ederer et al. 2006: 130), meaning with that the public's tendency to consider environments stable over time on one hand and, on the other hand, the tendency of reducing complex choices to ideological issues. Other reasons have been indicated to justify short-termism, particularly the saliency of immediate costs and benefits versus the uncertainty of the long-term ones, and the anticipation of future technological solutions for long-term problems (MacKenzie 2016a). Beyond these general arguments, reasons for short-termism of political systems were identified in the specific motivations of political actors, voters, politicians, and special interest groups and in the objective absence of future generations (MacKenzie 2016a).

In order to correct short-termism, a range of institutional solutions with an assessment of their effectiveness were presented (MacKenzie 2016a: 31), which could bind political actors to a long-term policy view or that could provide representation to future generations. The variety of institutional design solutions proposed, and their relative effectiveness with regard to different subjects, not only confirms the complexity of the problem, but also implies that a combination of different solutions might be the most effective in limiting short-termism and therefore in warrantying a degree of intergenerational equity, especially in response to long-term complex problems such as climate change (MacKenzie 2016a).

Attempts to rank the efficacy of different systems have also been carried out by other authors (Dirth 2018), who have ranked different institutional design solutions based on five qualities: independence, legitimacy, feasibility, accountability, and normative significance. These qualities were defined (Dirth 2018: 20-21) respectively as an institution which is not dependent or managed by another institution, which has the authority to intervene in the legislative process, which is accepted and supported by its context and thereby enabled to carry out its purpose in a sustainable fashion, which is accountable for its actions, therefore serving through enacting its norms in a transparent way, and, finally, which is capable of upholding the normative principles that underpin it.

Both the described approaches (Dirth 2018; MacKenzie 2016a) could provide a benchmark to assess different solutions, although it appears that the criteria chosen are susceptible of being defined in different ways. Moreover, the institutional designs that could be examined are partially undetermined and could be specified in a number of different variations, thereby making difficult to rank them. Empowering future generations and protecting them from short-term political visions is therefore necessary, but whatever institutions are chosen to do so, the following problems arise: "authorisation" and "accountability", which are compounded by the "epistemic problem" (Karnein 2016). Essentially, whatever agent should represent future generations, there is a problem of its authorisation and accountability because, clearly, future generations will not be capable of electing a body or holding its members in account for their decisions. At the same time, such institutions will be 
confronted with the complex problem of anticipating preferences and wishes of the future generations, and they will need to foresee the impact of policies as well as of their interventions in the policy formation process.

The problem of legitimacy of representation, i.e. authorisation, is not one that can be solved by institutional designs; it entails the philosophical debate that we have partly represented in earlier sections. It may suffice to say here that between the philosophical approaches earlier introduced, Ubuntu appears as the most suitable to attributing a moral legitimacy to this kind of surrogate representation, i.e. a representation in which the representative does not have any electoral relationship with the represented (Mansbridge 2011). In fact, the collective communitarian vision of Ubuntu could be considered, as we argued, far reaching and therefore capable of including future generations.

This representation of future generations' interests might be delivered in multiple ways, but inevitably, all are to some extent prone to a problem of misrepresentation, including the dishonest or anyway inaccurate representation of the interests at stake. The combination of different systems might reduce the problem of misrepresentation. Certainly, a more radical solution-perhaps the only one capable of avoiding the dangers of misrepresentation-would be to promote a cultural shift that would reframe the goal orientation of individuals and society from the satisfaction of immediate individual needs and wishes of accumulation (typical of anthropocentric perspective) towards an ecocentric one, which would recognise the dignity of natural systems to be preserved (Naess 1973). This shift from the individuals' pursuit of personal satisfaction or even accumulation is perhaps better facilitated by the Ubuntu's vision that holds all forms of life, human and non-human, and the natural wolrd as interconnected and worthy of being cherished and protected (see Lenkabula 2008; Chuwa 2014).

Other constitutional designs, which were and are used, and some that have been proposed, present solutions that appear worthy of mention. A first set are constitutional laws which are used in several countries. Tremmel (2006b) presents 21 examples of constitutional clauses that specifically target environmental protection; the oldest was adopted by Italy in 1947, but the majority of them were adopted from the 1970s onwards and mostly by European countries with the exceptions of Uruguay, Argentina, Brazil, and South Africa. More recently, Dirth (2018: 46) found 42 constitutions bearing clauses that aim to protect the environment for future generations, although only five of these have a legally binding wording and only two, Bhutan and Ecuador, make explicit reference to "intergenerational equity". In the case of Bhutan, we know by reading the preamble of the Environmental Protection Act (Kingdom of Bhutan 2007), for example, that environmental protection is embedded in a cultural environment promoting the so-called "development philosophy" of "gross national happiness". This, in turn, might have its historical routes in the search of a harmony with nature deriving from the acknowledgement of having a "...need to create institutional mechanisms to protect its fragile mountain ecosystem" (Kingdom of Bhutan 2007: 6). The Ecuadorian case seems to be the product of a long cultural process of recognition of the indigenous culture, and its inclusion in the institutional foundations of the Republic of Ecuador is explicit in the reference to social diversity and to the concept of "Pacha Mama", the deity of mother 
earth, revered by the indigenous people of the Andes, that is found in the preamble (National Assembly of Ecuador 2008).

The South African Constitution (Art. 24, RSA 1996: 9) makes explicit reference to rights of future generations: "Everyone has the right-(a) to an environment that is not harmful to their health or wellbeing; and (b) to have the environment protected, for the benefit of present and future generations, through reasonable legislative and other measures that-(i) prevent pollution and ecological degradation; (ii) promote conservation; and (iii) secure ecologically sustainable development and use of natural resources while promoting justifiable economic and social development". Cleary, from the explicit reference to sustainable development and the date of the document (1996), we can assume that the constitution and specifically Art. 24 were largely inspired by UN documents and debates about sustainable development. Nevertheless, as several authors pointed (Mokgoro 1998; Metz 2011), Ubuntu's values could be considered as a major influence over the constitution; therefore, it is not unfounded to hypothesise that the cosmocentric (Chuwa 2014) or ecocentric (Lenkabula 2008) vision of Ubuntu could have had a role in influencing the layout of Article 24.

Whether these significant constitutional provisions for environmental protection and the benefit of future generations are actually having a significant impact is a matter of debate. Observing the Environmental Performance Index (EPI) of the Yale Center for Environmental Law \& Policy (2018), we can observe that on 180 countries ranked worldwide, the earlier mentioned cases of Buthan, Ecuador, and South Africa ranked only 131, 87, and 142, respectively. European countries occupied the first 16 places of the rank with Switzerland, France, and Denmark leading. In this regard, these differences may not seem to reflect largely on the constitutional designs that are conceived to facilitate a high standard of environmental protection for current and future generation even in poorly ranked countries. Rather they might be attributable to the widely known environmental Kuznets curve (Kahn 2007), which describes how environmental degradation increases in developing economies up to plateau, corresponding to certain level of income per capita, before descending, thanks to programs of environmental protection that are then put in place and financed.

Clearly, constitutional clauses, despite being useful, might have a varying degree of efficacy, not only in relation to their wording, but also with regard to specific provisions that the constitution might make regarding the institutions that should enforce the specific principles aimed at protecting the environment and future generations. Further, we might consider general constitutional implementation issues and particularly the possibility of individuals and/or state institutions to challenge state legislations as unconstitutional. To be more specific, each individual state has a constitutionally established method of enforcing constitutional principles. Usually, these are enacted by constitutional courts that are called by other courts or institutions to settle controversies. It is safe to say that the more entitled subjects to appeal to a constitutional court there are, the more likely is that the constitutional provisions will be enforced. 
Another institutional design that is credited of having the potential of addressing intergenerational justice is the ombudsman for future generations (Beckman and Uggla 2016; Jávor 2006). The ombudsman was first experienced in Sweden in the early nineteenth century, and in recent years, several countries have experienced this institution in relation to environmental protection, future generations, and sustainability. The ombudsman can investigate the actions of state institutions and can recommend a course of action to relevant institutions; in some cases, it can initiate litigation taking to courts institutions whose actions or deliberations are considered against the interests that the ombudsman should protect, or it can delay legislation.

Beckman and Uggla (2016) point out that, far from being a weakness, the lack of definitive legislative power or judiciary authority of the ombudsmen may be a way to circumvent the problem of democratic legitimacy of the institution; in fact, democratic legitimacy is considered to rest solely on elected institutions; thereby only these are regarded of being entitled with legislative authority. In reality, it could be noted that significant powers to abolish or amend legislation are attributed to non-directly elected or non-elected bodies in many democratic states, both in common law and civil law systems (e.g. in the UK and Italy). Therefore, it could be possible to argue that even the ombudsman institution, opportunely appointed, could hold such powers. Perhaps, the major drawback of this system could be that the ombudsman is an authority which is concentrated in a single person or a restricted number of individuals (if its role is carried out by a commission like it was in Israel): this would make the institution not susceptible of exercising through multiple subjects its internal control, thereby possibly willingly or unwillingly missing some relevant legislative issues. Finally, it is arguable that being nominated by the parliament would make the institution prone to fall into the control of the parliamentary majority and therefore would incur the risk of being in line with the government. This could happen, unless a qualified majority rule is used in order to guarantee the choice of an individual representing, to some extent, the parliamentary minorities.

The third main system for protecting future generations that has been proposed, and in some cases implemented (particularly through youth quotas), regards the possibility of altering the composition of the parliament creating quotas for individuals who are supposed to represent the interests of future generations (Dirth 2018). Youth quotas are one of the means that were used for this purpose, but as duly noted by Dirth (2018) and MacKenzie (2016a), they do not appear effective, primarily because young generations will not extend much in the future the consideration of current problems and secondarily because they might be concerned with present needs as much as adults. Another, arguably more effective solution is that proposed by Dobson (1996: 132-135), a system where the interests of future generations would be protected by, what he calls, a constituency of proxy electors and proxy elected representatives, both of which would belong to the environmental movement or "lobby" (Dobson 1996: 133). Dobson admits that the composition of this lobby would be hard to determine, and this last point, among others, might actually be the main problem with Dobson's proposal. Beyond that, there is also a matter of 
democratic legitimacy: selecting a proxy electorate based on green attitudes clearly attributes a higher status to green lobby's members who would get to vote both for the general parliament and for the future generations' representation seats. Obviously, this is at odds with the principles of universal suffrage and ultimately of formal equality and procedural justice, indicated by several authors as founding principles of energy justice (see McCauley et al. 2013; Pellegrini-Masini et al. 2019b). In fact, energy justice, as it has been argued (McCauley et al. 2013), should be founded on the tenet of procedural justice among others, which implies the equal rights (formal equality) of all citizens to contribute to the process of formation of energy policies. Having a number of citizens that because of their belonging to the green lobby would get two votes for the parliament and twice the opportunity of standing as candidates clearly circumvents the principle of formal equality of citizens that is at the core of modern democracies.

Another noteworthy proposal of parliamentary representation of future generations, which could circumvent the problem of infringing the principles of formal equality and procedural justice, would be the one proposed by Mackenzie (2016b: 282-283) of a "general purpose randomly-selected chamber". This proposal entails the selection of citizens through a stratified random process suitable to adequately represent "each politically relevant group", who would act in the interest of future generations. This chamber would be an addition to the main chamber of the parliament, which would have "soft powers", i.e. the possibility of delaying legislation (albeit not indefinitely), the ability of proposing amendments to legislation, and the possibility of "holding government in account" (MacKenzie 2016b: 283). In some respects, this proposal is undoubtedly attractive, because it would offer the possibility, even for ordinary individuals not belonging to political lobbies, to join the parliament, therefore respecting radically the principle of formal equality and procedural justice. Nevertheless, it is also worth observing that problems might arise in polarised political communities, where it is imaginable that the randomly selected members of parliament would possibly coordinate their activities with those political groups of the elected chamber that show the highest degree of affinity with their political views. Secondarily, in countries with high levels of corruption, it is imaginable that ordinary citizens without structured political views might fall for offering their support in exchange for some benefits.

The last parliamentary design that we wish to mention is the sub-majority rule model of Ekeli (2016), who proposes that parliament's minorities could be given the privileges to advocate for future generations' interests. These powers would be essentially twofold: the first would grant to a minority of at least a third of the chamber to delay contested legislation up to the next election, while the second would allow the same minority to demand a referendum to submit the final decision about a contested bill to voters. While the rationale of Ekeli is clear, and the proposal's respect of citizens' formal equality is evident, the criticism that could be moved is that there is no guarantee that experienced politicians might not use these rules to score political points against their adversaries, even when these powers are allowed only for cases of legislative proposals regarding future generations. In fact, arguably, a vast number of bills could be considered to have some degree of consequences for future generations. 
In this section of the chapter, we have attempted to discuss institutional solutions for establishing intergenerational energy justice. While it is clear that there is a wide number of solutions, a few overarching points can be made: (1) intergenerational energy justice would be most likely implemented through a variety of institutional designs that aim to represent future generations' interests with regard to all the state legislation affecting current societal issues; (2) a combination of different institutional designs might be preferable for overcoming the shortcomings of each single design; (3) considering that formal equality and procedural justice might be regarded as core principles of energy justice, it is arguable that any institutional design which aims to fulfil energy justice with regard to future generations would be chosen attempting to uphold these principles. In this respect, it could be said that constitutional clauses enforceable by the initiative of multiple actors and some of the parliamentary designs that do not advantage specific lobbies would embody these principles more than the institution of the ombudsman, unless a large qualified parliamentary majority elects the ombudsman. In this case, although being a secondary elected body, it could be considered as having a reasonably wide democratic legitimacy.

\subsection{Conclusions}

The question of how future generations should be included in the group of individuals whose rights and duties should be taken into consideration in energy justice cannot be answered in a simple way. As we have seen, the philosophical underpinnings of future generations' rights face significant challenges. The various branches of contractualism struggle to find a coherent formulation of an intergenerational contract that both fits with our considered intuitions on human motivation and the plausibility of the contractual metaphor. The Ubuntu concept of a shared community, which is for many scholars intuitively fitting for human social relations, cannot circumvent trade-off situations and does not provide processes for managing such trade-offs.

Despite the weak arguably philosophical underpinnings of our chapter, our intuitions are relatively stable. It is few who deny that future generations have some moral worth and that our contemporary actions need to take this worth into account. There are several concrete policy proposals to make our institutions more adaptable to the challenges of long-term complex issues such a climate change. It is thus reasonable to say that the main problem facing intergenerational equity's implementation is not exclusively a philosophical problem, but also a policy one. Despite it being evident that there are problems in the philosophical conceptions of intergenerational justice, it is nevertheless difficult to trace any substantial stance against intergenerational justice in the academic literature, if not perhaps in some minority positions taken by radical contractualist libertarians, who disavow any rights of future generations, because they are considered simply as non-existing subjects. Therefore, in the presence of a reasonably wide agreement in academic and policy circles towards the need of protecting the rights of future generations, demonstrated also by the widely recognised UN sustainable development goals (UN 2015), the main hurdle for implementation rests on the choice of the most 
effective institutional designs to achieve it. The effectiveness of this might change across different geographical and therefore cultural environments.

The choice of the most effective designs might be a complicated one and to some extent might be also linked to peculiar cultural-political environments. As we observed earlier, a combination of several institutional instruments might be the one that is most likely to deliver some degree of success. What perhaps can be stressed here is that the mere presence of institutional instruments devoted to ensure some degree of protection of future generations' environmental rights is far from being a guarantee that this protection will actually be implemented. A matter that might be paramount is to ensure an effective implementation with regard to the issues of agency and legitimacy of those who can exercise the actions necessary to protect those rights. This point also holds true to the philosophical underpinnings of such institutions. That a concept such as Ubuntu can be used to justify care for future generations does not clearly correlate to actual care for those generations. If a contractual interpretation of our responsibility towards future generations is more in tune with public sentiments and motivates this public to take concrete ways for protecting future generations, there is a pragmatic case in support of this interpretation.

Finally, the relation of specific institutional instruments with the legislative and the judiciary powers is important, as is their ability to hold governments in account. Therefore, broadening the agency base of the actors capable of initiating actions to defend future generations' rights and, at the same time, affording full legitimacy to the institution(s) that should enforce those rights, whether embedding it (or them) in the recognised legislative and/or judiciary powers, seem to be the only choices that could maximise the likelihood of and effective protection of future generations.

\section{References}

Ashford, E. (2003). The demandingness of Scanlon's contractualism. Ethics, 113(2), 273.

Ashford, E. (2018). Contractualism. In Edward N. Zalta (Ed.), The Stanford encyclopedia of philosophy (summer 2018 edition). Retrieved from https://plato.stanford.edu/archives/ sum2018/entries/contractualism/.

Beckman, L., \& Uggla, F. (2016). An ombudsman for future generations-legitimate and effective? In I. González-Ricoy \& A. Gosseries (Eds.), Institutions for future generations. Oxford: Oxford University Press.

Behrens, K. G. (2012). Moral obligations towards future generations in African thought. Journal of Global Ethics, 8(2-3), 179-191.

Sovacool, B. K., Burke, M., Baker, L., Kotikalapudi, C. K., \& Wlokas, H. (2017). New frontiers and conceptual frameworks for energy justice. Energy Policy, 105, 677-691.

Chachine, I. E. (2008). Community, justice, and freedom. Liberalism, communitarianism, and African contributions to political ethics. Acta Universitatis Upsaliensis. Uppsala Studies in Social Ethics, 37.

Chuwa, L. T. (2014). African indigenous ethics in global bioethics. Dordrecht: Springer.

Cudd, A., \& Eftekhari, S. (2018). Contractarianism. In Edward N. Zalta (Ed.), The Stanford encyclopedia of philosophy (summer 2018 edition). Retrieved from https://plato.stanford.edu/ archives/sum2018/entries/contractarianism/.

De-Shalit, A. (1995). Why posterity matters: Environmental policies and future generations. London: Routledge. 
Dirth, E. (2018). A global review of the implementation of intergenerational equity. Utrecht University.

Dobson, A. (1996). Representative democracy and the environment. In W. M. Lafferty \& J. Meadowcroft (Eds.), Democracy and the environment: Problems and prospects (pp. 124139). Cheltenham: Edward Elgar.

Ederer, P., Schuller, P., \& Willm, S. (2006). The economic sustainability indicator. In J. C. Tremmel (Ed.), Handbook of intergenerational justice. Cheltenham: Edward Elgar.

Ekeli, K. S. (2016). Electoral design, sub-majority rules and representation for future generations. In I. González-Ricoy \& A. Gosseries (Eds.), Institutions for future generations. Oxford: Oxford University Press.

Eze, M. O. (2008). What is African communitarianism? Against consensus as a regulative ideal. South African Journal of Philosophy, 27(4), 386-399.

Gardiner, S. M. (2009). A contract on future generations? In A. Gosseries \& L. M. Meyer (Eds.), Intergenerational justice. Oxford: Oxford University Press.

Gauthier, D. (1987). Morals by agreement. Oxford: Clarendon Press.

Heyd, D. (2009). A value or an obligation? Rawls on justice to future generations. In A. Gosseries \& L. M. Meyer (Eds.), Intergenerational justice. Oxford: Oxford University Press.

Jávor, B. (2006). Institutional protection of succeeding generations-Ombudsman for future generations in Hungary. In Handbook of intergenerational justice. Cheltenham: Edward Elgar.

Kahn, M. E. (2007). Green cities: Urban growth and the environment. Washington, DC: Brookings Institution Press.

Karnein, A. (2016). Can we represent future generations? In I. González-Ricoy \& A. Gosseries (Eds.), Institutions for future generations. Oxford: Oxford University Press.

Kingdom of Bhutan. (2007). The National Environment Protection Act of Bhutan, 2007. Retrieved from http://www.nec.gov.bt/nec1/wp-content/uploads/2012/10/NEPA-_ENG.pdf.

Lenkabula, P. (2008). Beyond anthropocentricity-Botho/Ubuntu and the quest for economic and ecological justice in Africa. Religion and Theology, 15, 375-394. https://doi.org/10.1163/157 $430108 X 376591$.

MacIntyre, A. (1989). Whose justice which rationality. Notre Dame, IN: University of Notre Dame Press.

MacIntyre, A. (2006). After virtue: A study of moral theory (2nd ed.). London: Duckworth.

MacKenzie, M. K. (2016a). Institutional design and sources of short-termism. In I. GonzálezRicoy \& A. Gosseries (Eds.), Institutions for future generations. Oxford: Oxford University Press.

MacKenzie, M. K. (2016b). A general-purpose, randomly selected chamber. In I. González-Ricoy \& A. Gosseries (Eds.), Institutions for future generations. Oxford: Oxford University Press.

Mansbridge, J. (2011). Clarifying the concept of representation. The American Political Science Review, 105, 621-630. https://doi.org/10.1017/S0003055411000189.

Matolino, B. (2009). Radicals versus moderates: A critique of Gyekye's moderate communitarianism. South African Journal of Philosophy, 28(2), 160-170.

Matolino, B., \& Kwindingwi, W. (2013). The end of Ubuntu. South African Journal of Philosophy, 32(2), 197-205.

Mbiti, J. S. (1969). African religion and philosophy. London: Heinemann.

McCauley, D. (2018). Energy justice re-balancing the trilemma of security, poverty and climate change. London: Palgrave Macmillan. https://doi.org/10.1007/978-3-319-62494-5.

McCauley, D., Heffron, R. J., Stephan, H., \& Jenkins, K. (2013). Advancing energy justice: The triumvirate of tenets and systems thinking. International Energy Law Review, 32, 107-110.

Menkiti, I. (2017). Community, communism, communitarianism: An African intervention. In A. Afolayan \& T. Falola (Eds.), The Palgrave handbook of African philosophy (pp. 461-471).

Metz, T. (2011). Ubuntu as a moral theory and human rights in South Africa. African Human Rights Law Journal, 5(2), 532-559.

Metz, T. (2014). Just the beginning for Ubuntu: Reply to Matolino and Kwindingwi. South African Journal of Philosophy, 33(1), 65-72.

Mokgoro, J. Y. (1998). Ubuntu and the law in South Africa. Potchefstroom Electronic Law Journal/ Potchefstroomse Elektroniese Regsblad, 1, 1. 
Naess, A. (1973). The shallow and the deep, long-range ecology movement: A summary. Inquiry: An Interdisciplinary Journal of Philosophy, 16, 95-100. https://doi.org/10.1080/ 00201747308601682.

Nagel, T. (1989). The view from nowhere. Oxford: Oxford University Press.

National Assembly, Constitution of the Republic of Ecuador. (2008). Constitution: Leave the past back. República del Ecuador.

Pellegrini-Masini, G., Pirni, A., \& Maran, S. (2019a). Delivering a timely and just energy transition: Which policy research priorities? Under review.

Pellegrini-Masini, G., Pirni, A., Maran, S. (2019b). Energy justice revisited: A critical review on the philosophical and political origins of equality. Forthcoming in Energy Research and Social Science.

Praeg, L. (2008). An answer to the question: What is [Ubuntu]? South African Journal of Philosophy, 27(4), 367-385.

Rawls, J. (1971). A theory of justice. Oxford: Oxford University Press.

Rawls, J. (1999). A theory of justice (2nd revised ed.). Cambridge, MA: The Belknap Press of Harvard University Press.

Rawls, J. (2005). Political liberalism-Expanded edition. New York: Columbia University Press.

RSA. (1996). The Constitution of the Republic of South Africa. https://doi.org/10.1017/ S0021855300011499

Sandel, M. (1981). Liberalism and the limits of justice. Cambridge: Cambridge University Press.

Scanlon, T. M. (1998). What we owe to each other. Cambridge MA: The Belknap Press of Harvard University Press.

Sono, T. (1994). Dilemmas of African intellectuals in South Africa. Pretoria: UNISA.

Southwood, N. (2009). Moral contractualism. Philosophy Compass, 4(6), 926.

Taylor, C. (1989). Sources of the self: The making of the modern identity. Cambridge: Cambridge University Press.

Tremmel, J. C. (2006a). Handbook of intergenerational justice. Cheltenham: Edward Elgar.

Tremmel, J. C. (2006b). Establishing intergenerational justice in national constitutions. In J. C. Tremmel (Ed.), Handbook of intergenerational justice (pp. 187-214). Cheltenham: Edward Elgar.

UN General Assembly. (2015). Transforming our world: The 2030 Agenda for Sustainable Development.

Walzer, M. (1983). Spheres of justice. Oxford: Blackwell.

Open Access This chapter is licensed under the terms of the Creative Commons Attribution 4.0 International License (http://creativecommons.org/licenses/by/4.0/), which permits use, sharing, adaptation, distribution and reproduction in any medium or format, as long as you give appropriate credit to the original author(s) and the source, provide a link to the Creative Commons license and indicate if changes were made.

The images or other third party material in this chapter are included in the chapter's Creative Commons license, unless indicated otherwise in a credit line to the material. If material is not included in the chapter's Creative Commons license and your intended use is not permitted by statutory regulation or exceeds the permitted use, you will need to obtain permission directly from the copyright holder.

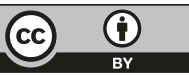

